\title{
Elevated glucose decreases the content of a basement membrane associated heparan sulphate proteoglycan in proliferating cultured porcine mesangial cells
}

\author{
B. Olgemöller, S. Schwaabe, K.D. Gerbitz and E.D. Schleicher \\ Institute für Klinische Chemie und Diabetesforschung, Städtisches Krankenhaus Schwabing, München, FRG
}

\begin{abstract}
Summary. The effect of elevated glucose concentrations on the synthesis of basement membrane components was investigated in proliferating cultured porcine mesangial cells. Basement membrane associated heparan sulphate proteoglycan was determined by enzyme immunoassay with a specific antiserum recognizing the core protein of the heparan sulphate proteoglycan. When cells were exposed to increasing glucose concentrations up to $40 \mathrm{mmol} / \mathrm{l}$, the heparan sulphate proteoglycan content was concomitantly decreased to $53 \%$ when compared to cells cultured under normal glucose concentrations or in the presence of $40 \mathrm{mmol} / 1$ sorbitol. The fibronectin content was essentially unchanged under these
\end{abstract}

conditions. No significant effect of insulin on these basement membrane components was found. The results indicate that hyperglycaemia may be responsible for a decrease of mesangial heparan sulphate proteoglycan content in diabetes mellitus. This supports the view that loss of heparan sulphate proteoglycan may be an important step or even an initial event of mesangial alterations in diabetic glomerulopathy.

Key words: Diabetes mellitus, nephropathy, glomerular mesangial cells, heparan sulphate proteoglycan, hyperglycaemia.
Thickening of the mesangial matrix is an early event in the genesis of diabetic nephropathy. Changes of mesangial matrix composition in diabetes mellitus have been reported recently [1]. Especially, increased synthesis of collagen type IV [2] and other matrix constituents [3] have been demonstrated in rat mesangial cells cultured in high glucose medium. Basement membrane associated heparan sulphate proteoglycan (HSPG) is believed to play a key role in the development of diabetic glomerulopathy. A decreased content of HSPG in basement membrane is thought to be responsible for increased macromolecular permeability of diabetic glomerula [4]. However, the glomerular basement membrane and the mesangial matrix are two morphologically and biosynthetically distinct zones of extracellular matrix with a separate developmental origin. The question, whether loss of HSPG is a characteristic of mesangial thickening or may even be the trigger for a compensatory synthesis of other matrix components, remains to be elucidated.

Since little is known about HSPG synthesis of mesangial cells, we have examined their ability to produce HSPG under various growth conditions, including growth in high glucose medium.

\section{Materials and methods}

\section{Materials}

Media, supplements and fetal calf serum for tissue culture were obtained from Gibco Europe (Karlsruhe, FRG), insulin and trypsin were from Serva (Heidelberg, FRG). Fibronectin antiserum and goat anti-rabbit IgG were purchased from Behringwerke (Marburg, FRG). HSPG antiserum from rabbit was prepared and characterized as described $[5,6]$. All other biochemicals were from Sigma (Taufkirchen, FRG).

\section{Cell culture}

Porcine mesangial cells (PMC) were obtained from porcine glomeruli [7], Glomeruli were isolated by serial sieving of cortical pieces and suspended in Medium 199 (Earle's Salts) supplemented with $20 \%$ fetal calf serum, $100 \mathrm{U} / \mathrm{ml}$ penicillin, $100 \mu \mathrm{g} / \mathrm{ml}$ streptomycin, $3 \mathrm{mmol} / \mathrm{l}$ glutamine under a $5 \% \mathrm{CO}_{2}$ atmosphere. After 7 days in culture glomeruli were picked and discarded. Outgrowing cells were subcultured after detachment with $0.01 \%$ trypsin and $0.02 \%$ EDTA in phosphate-buffered saline (PBS).

PMC were characterized by their morphological and biochemical characteristics according to previously described methods [7]. For the experiments, cultures from the 6-8th passage were plated on 

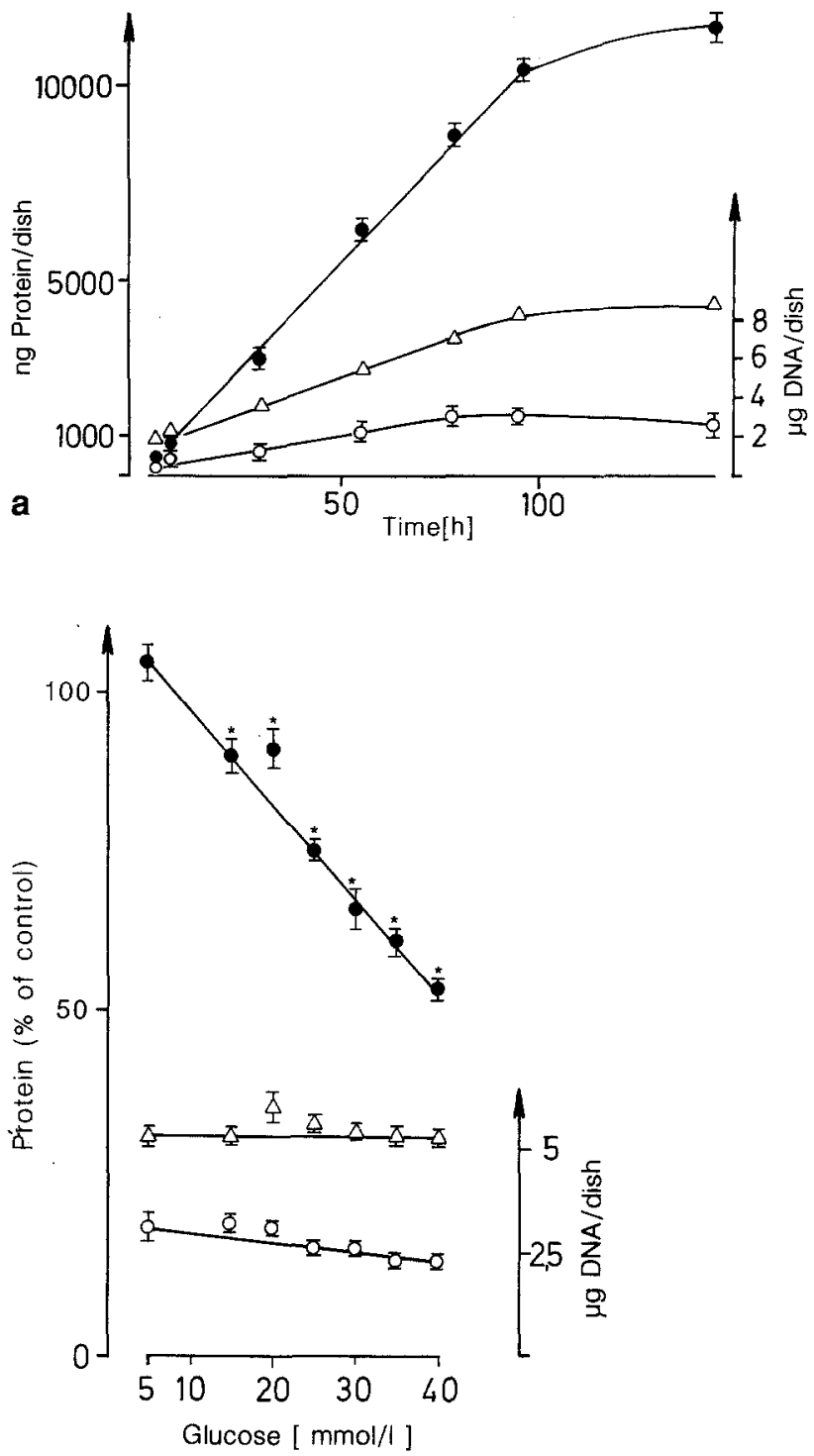

Fig. 1a,b. a Heparan sulphate proteoglycan ( $)$ and fibronectin (O) content during growth of porcine mesangial cells (PMC): cultures were harvested after various periods of time and analysed for DNA $(\Delta)$ and content of matrix components. Data are expressed as mean \pm SEM of four dishes. $b$ Influence of glucose concentration in the growth medium on heparan sulphate proteoglycan $(\mathbf{O})$, fibronectin $(O)$ and DNA $(\triangle)$ content of PMC. Cells obtained by trypsinisation were plated and harvested at pre-confluence after $48 \mathrm{~h}$. Data represent mean $\pm \mathrm{SEM}$ of four dishes each. ${ }^{*} p<0.05$ vs $5 \mathrm{mmol} / \mathrm{l}$ glucose

$24 \mathrm{~mm}$ six-well plates (split ratio 1:2 after trypsinisation). Then the cells were exposed to increasing glucose levels. All media were corrected with $\mathrm{NaCl}$ for constant osmolarity ( $300 \mathrm{mosmol} / \mathrm{l})$. During the experiments, medium was changed every $12 \mathrm{~h}$. Incubations were terminated after $48 \mathrm{~h}$ and cells were solubilized with guanidinium$\mathrm{HCl}$ solution containing protease inhibitors.

\section{Determination of basement membrane components}

Total matrix associated HSPG and fibronectin were determined by enzyme immunoassay as described [6]. Before harvesting, cells were washed three times with PBS. The cell layer was then incubated with $0.6 \mathrm{ml} 4 \mathrm{~mol} / 1$ guanidinium $-\mathrm{HCl}$ containing $0.5 \%$ Chaps and protease inhibitors $(1 \mathrm{mmol} / \mathrm{l}$ phenylmethylsulphonyl fluoride, $10 \mathrm{mmol} / \mathrm{l} \quad \mathrm{N}$-ethyl-maleimide, $10 \mathrm{mmol} / \mathrm{l} \quad$ EDTA $10 \mathrm{mmol} / \mathrm{l}$ 6-amino-hexanoic acid, $5 \mathrm{mmol} / \mathrm{l}$ benzamidine- $\mathrm{HCl}$ ) for $1 \mathrm{~h}$ at room temperature. Solubilisation was examined by phasecontrast microscopy to ensure total cellular disruption. Samples were stored at $-30^{\circ} \mathrm{C}$ until measurement. After 1:100 dilution with PBS a $100 \mu \mathrm{l}$ aliquot was used to coat each well (multiwell chambers from Nunc, Roskilde, Denmark). The appropriate antiserum was then added. A peroxidase-labelled goat anti-rabbit IgG was used as second antibody. For calibration, fibronectin prepared from porcine plasma and HSPG isolated from porcine glomerular basement membrane [6] were used.

HSPG was glycated in vitro with 5 and $40 \mathrm{mmol} / \mathrm{l}$ glucose for $48 \mathrm{~h}$. Sorbitol was used as control. The degree of glycation was assessed by determination of furosine in acid hydrolysates of the glycated HSPG by high pressure chromatography on reverse phase.

DNA content of the cell pellets was measured in parallel incubations by the colour reaction with diphenylamine and paraldehyde. Lactate production was determined enzymatically with lactate dehydrogenase and alanine aminotransferase in pooled medium supernatants.

\section{Statistical analysis}

Data are given as means $\pm S E M$. The Mann-Whitney U test was used to test differences between experimental conditions.

\section{Results}

Confluent cultures of PMC were trypsinized and seeded with a plating density of about $0.6 \mu \mathrm{g} \mathrm{DNA} / \mathrm{cm}^{2}$. Cells were harvested after various periods of time and the amount of HSPG and fibronectin associated with the cultures was determined. As can be seen from Figure $1 \mathrm{a}$ in comparison with the DNA content of the cultures, these basement membrane components were synthesized during the logarithmic phase of growth. When cells reached confluence, curves for DNA, HSPG and fibronectin plateaued. In order to measure synthesis of basement membrane material, incubations with varying medium conditions were initiated $2 \mathrm{~h}$ after seeding when cells were firmly attached to the plates. Media were changed every $12 \mathrm{~h}$ since longer intervals led to glucose deprivation of endothelial cells when incubated in normal glucose levels and to acidification of media.

The production of HSPG in PMC was influenced by the ambient glucose concentration. In six different experiments, incubation with $40 \mathrm{mmol} / 1$ glucose reduced the HSPG content to $45-60 \%$ of control values $(5 \mathrm{mmol} / 1$ glucose). Figure $1 \mathrm{~b}$ shows the results of one typical experiment. The HSPG content was not influenced by $40 \mathrm{mmol} / 1$ sorbitol (Table 1 ). Elevated glucose concentrations had no significant effect on the fibronectin content of the cultured cells. To determine whether high glucose concentrations were impairing basic cellular functions such as proliferation or metabolic activity, DNA content of the cultures and their lactate production were measured. DNA content of the cultures was constant for all glucose concentrations (Fig. 1b). Glucose concentration did not disturb metabolic activity as assessed by lactate formation. For example, 2.1 vs $2.3 \mu \mathrm{mol}$ lactate $/ 48 \mathrm{~h} \times \mu \mathrm{g}$ DNA were found for 5 and $40 \mathrm{mmol} / 1$ glucose, respectively. Insulin 
Table 1. Effect of different medium conditions on heparan sulphate proteoglycan (HSPG) content of porcine mesangial cells (PMC) $48 \mathrm{~h}$ after passage. Results are given as mean $\pm \mathrm{SEM}$ of four dishes each

\begin{tabular}{|c|c|}
\hline Media conditions & HSPG (ng/dish) \\
\hline $5 \mathrm{mmol} / \mathrm{l}[\mathrm{D}]$-glucose (control) & $5340 \pm 374$ \\
\hline $5 \mathrm{mmol} / \mathrm{l}[\mathrm{D}]-\mathrm{glucose}+$ insulin ${ }^{\mathrm{a}}$ & $4965 \pm 183^{b}$ \\
\hline $40 \mathrm{mmol} / 1[\mathrm{D}]$-glucose & $2820 \pm 123^{\mathrm{c}}$ \\
\hline $40 \mathrm{mmol} / \mathrm{l}[\mathrm{D}]$-glucose + insulin ${ }^{\mathrm{a}}$ & $2927 \pm 59^{c, d}$ \\
\hline $40 \mathrm{mmol} / 1$ sorbitol & $5080 \pm 301^{\mathrm{b}}$ \\
\hline
\end{tabular}

did not significantly modify HSPG or fibronectin content of PMC at either 5 or $40 \mathrm{mmol} / \mathrm{l}$ glucose in the incubation medium (Table 1).

\section{Discussion}

Our results demonstrate that elevated glucose impaired the content of HSPG in proliferating cultured mesangial cells. Decrease of HSPG was not due to metabolic disturbance or decreased cell number since no effect was found in lactate production and DNA content, respectively, indicating that the decrease in HSPG content is not a general effect of glucose toxicity. The effect was also not caused by osmotic disturbances as all media were corrected for constant osmolarity with $\mathrm{NaCl}$, and as in control incubation with $40 \mathrm{mmol} / 1$ sorbitol HSPG content was not altered. The possibility that increased non-enzymatic glycation of HSPG leads to decreased antigen-antibody binding was ruled out. When HSPG was glycated in vitro to an extent similar to that expected to occur in the cell culture experiments, no change in antibody binding was found (data not shown). The diminution of HSPG production in PMC was selective since the level of fibronectin was essentially unchanged. Lower HSPG content of PMC may not only be the result of decreased synthesis but may also be due to increased degradation. The fact that accumulation of basement membrane material paralleled the increase in DNA content during the logarithmic phase of cell growth may support the view that impaired synthesis rather than accelerated degradation was responsible for the influence of glucose on HSPG content in our experiments.

Most of our knowledge on reduced HSPG content in diabetes is based on studies in glomerula of diabetic animals or human patients. For example, decreased incorporation of ${ }^{35} \mathrm{SO}_{4}$ into glomerular basement membrane and its accelerated removal have both been reported in diabetic animals. Using specific antibodies against a basement membrane heparan sulphate from a mouse tumour, Shimomura and Spiro showed reduced heparan sulphate content but unchanged fibronectin levels in diabetic human glomeruli [8]. Immunohistochemical studies from our group on glomerular structures obtained from diabetic subjects with nephropathy showed a massive decrease of HSPG (unpublished/observation). Recently, it was reported that mRNA levels encoding for HSPG were lower in kidney cortices of diabetic mice if compared to control animals [9]. None of these studies differentiates between the peripheral glomerular basement membrane and the mesangial matrix, both affected by the changes associated with diabetes. Recently, it was reported that proliferating glomerular mesangial cells synthesize extracellular matrix components similar to that seen in the glomerular mesangium in vivo [3]. Furthermore, increased production of collagen type IV [2,3], laminin [3] and fibronectin [3] has been reported in rat mesangial cells when grown in high glucose medium for 12 [2] or 7 [3] days, respectively. The latter observation concerning fibronectin is different from that which we observed and may be due to different experimental design since we measured fibronectin content after short incubation times during the logarithmic phase of growth ( $48 \mathrm{~h}$ ).

Insulin did not influence HSPG content in our experiments independent of the ambient glucose level. This is in accordance with reports on unchanged ${ }^{35} \mathrm{SO}_{4}$-incorporation into cultured cells from Engelbreth-Holm-Swarm tumour upon incubation with insulin [10].

Alterations of mesangial matrix composition may have severe functional consequences. Decreased HSPG content may trigger mesangial cell proliferation, since inhibition of mesenchymal cell proliferation by heparan sulphate is well documented. Accelerated proliferation of mesangial cells has been identified as part of mesangial dysregulation in diabetic glomerulopathy [1]. Furthermore, by virtue of its heparan sulphate side chains, HSPG can complex different molecules, e.g. basic fibroblast growth factor, and may modulate their biologic activity.

In analogy to the hypothesis of Rohrbach et al. [4], who proposed that metabolic derangement in diabetes induces the loss of HSPG in the glomerular basement membrane and that this loss may be the underlying cause for the increase in production of other basement membrane material, our results suggest that this mechanism also holds true for the dysregulation of matrix composition during mesangial thickening. A loss of HSPG may even trigger a compensatory overshooting synthesis of other extracellular matrix components by a hitherto unknown mechanism.

Acknowledgements. The excellent technical assistance of Ms. E. Wagner is gratefully acknowledged. We thank Dr. T. Ladik for advice concerning statistical analysis. This study was supported by grants from the Deutsche Forschungsgemeinschaft (0148/1-3 and Sch1 239/1-3).

\section{References}

1. Striker LJ, Conti FG, Doi T, Elliot SJ, Striker GE (1991) Kidney disease of diabetes mellitus: the contribution of glomerular mesangial cells to the glomerulosclerosis. In: Andreani D, Gueriguian JL, Striker GE (eds) Diabetic complications; Serono Symposia Publications from Raven Press, Vol. 69. Raven Press, New York, pp 131-143

2. Haneda M, Kikkawa R, Hortide N et al. (1991) Glucose enhances type IV collagen production in cultured rat glomerular mesangial cells. Diabetologia 34: 198-200

3. Ayo SH, Radnik RA, Glass WF II et al. (1990) Increased extracellular matrix synthesis and mRNA in mesangial cells grown in high-glucose medium. Am J Phys 260: F185-F191 
4. Rohrbach DH, Hassell JR, Kleinman HK, Martin GR (1982) Alterations in the basement membrane (heparan sulphate) proteoglycan in diabetic mice. Diabetes 31:185-188

5. Schleicher ED, Wagner EM, Olgemöller B, Nerlich AG, Gerbitz KD (1989) Characterization and localization of basement membrane-associated heparan sulphate proteoglycan in human tissues. Lab Invest 61: 323-332

6. Olgemöller B, Schleicher E, Nerlich A, Wagner EM, Gerbitz KD (1989) Isolation, characterization and immunological determination of basement membrane-associated heparan sulphate proteoglycan. Biol Chem Hoppe-Seyler 370: 1321-1329

7. Striker GE, Striker LJ (1985) Glomerular cell culture. Lab Invest 53: 122-131

8. Shimomura S, Spiro RG (1987) Studies on macromolecular components of human glomerular basement membrane and alterations in diabetes: decreased levels of heparan sulphate proteoglycan and laminin. Diabetes 36: 374-381
9. Ledbetter SR, Copeland EJ, Noonan D, Vogeli G, Hassel JR (1990) Altered steady-state in mRNA levels of basement membrane proteins in diabetic mouse kidneys and thromboxane synthase inhibition. Diabetes 39: 196-203

10. Ledbetter SR, Wagner CW, Martin GR, Rohrbach DH, Hassell JR (1987) Response of diabetic basement membrane-producing cells to glucose and insulin. Diabetes 36: 1029-1034

Received: 9 September 1991

and in revised form: 28 October 1991

Dr. B. Olgemöller

Institut für Klinische Chemie

Kölner Platz 1

W-8000 München 40

FRG 